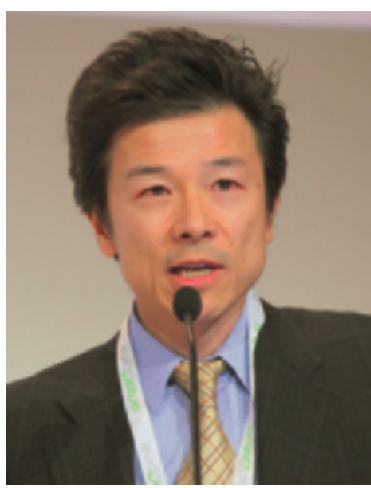

_ Prof. K. Hasegawa

\title{
Final comments of the Symposium President on ArgoSpine 2011
}

Thanks to all of the participants, the last ArgoSpine Symposium 2011, which was held at the Pullman Paris Tour Eiffel Hotel on January 27th and 28th ended successfully. Lectures by the invited speakers with interactive discussions were excellent and enthusiastic around the main theme of "Evidence-based spine surgery: myth or reality?"

Evidence-based medicine (EBM) aims to apply the best available evidence gained from the scientific method to medical decision-making in treatments and diagnostic tests. EBM recognizes that many aspects of medical care depend on individual factors such as quality-of-life judgments, which are only partially subject to scientific methods. EBM, however, seeks to clarify those parts of medical practice that are in principle submitted to scientific methods and to apply these methods to ensure the best prediction of outcomes in medical treatments.

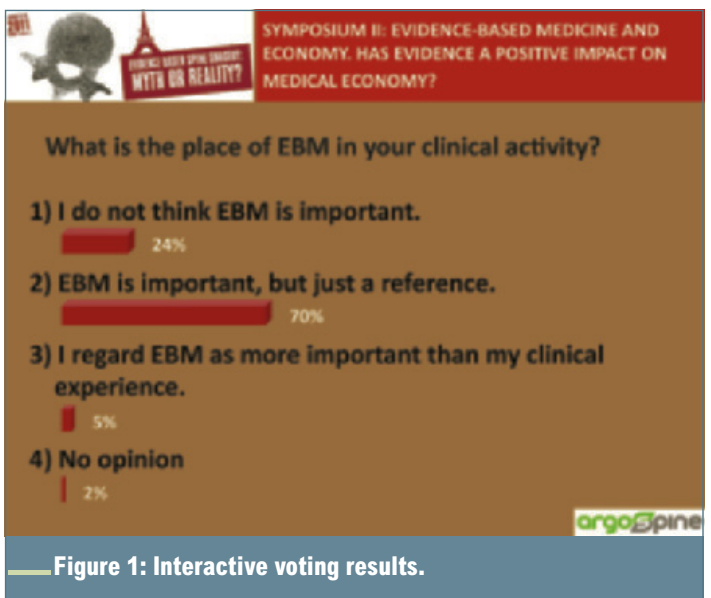

We must, however, stop here and ask ourselves: "What does EBM mean for us, spine surgeons?" During the symposium, Prof. Dubousset presented his philosophy that "EBM is not applicable to a specific patient" and "One honest observation is better than one hundred 'cutting off' statistics!". Following presentations in the session, we asked a question: "What is the place of EBM in your clinical activity?". The majority of the participants expressed their standpoint as: "I do not think EBM is important" or "EBM is important, but just a reference" (Figure 1). This suggests that although EBM is necessary for research as a measure, most of the spine surgeons agree that we stand in a view of patient-based medicine rather than statistics-based medicine.

Now is the time it should be reminded of the Hippocratic Oath: "I will prescribe regimens for the good of my patients (...). I will not give a lethal drug to anyone if I am asked (...). But I will preserve the purity of my life and my arts. I will not cut for stone, even for patients in whom the disease is manifest; I will leave this operation to be performed by practitioners, specialists in this art. In every house where I come I will enter only for the good of my patients (...). All that may come to my knowledge in the exercise of my profession (...) I will keep secret and will never reveal. If I keep this oath faithfully, may I enjoy my life and practice my art, respected by all men and in all times; but if I swerve from it or violate it, may the reverse be my lot."

A maxim $\mathbf{z}$ 以 - which was mounted on the top of the programme means: "Let us live through in accordance with a faith, consideration to others." If we replace "faith" with the Hippocrates' Oath, then we are able to achieve the aims of ArgoSpine: 1) Promoting the knowledge by all means of techniques for the treatment of spinal disorders and the various means for the objective assessment of the effectiveness of the treatment; 2) Fostering pure and applied research in the area of the treatment of spinal disorders.

Finally, I would like to express my gratitude to all the participants to ArgoSpine 2011 ; I am glad and honoured to pass on the job to Prof. Carlos Villas, the next President in 2012, with great expectations for the further development of our society. Looking forward to seeing you again in Paris! •

Prof. K. Hasegawa 